\title{
Management of Fibrosing Interstitial Lung Diseases
}

\author{
Toby M. Maher (D) Wim Wuyts
}

Received: April 10, 2019 / Published online: May 22, 2019

(C) The Author(s) 2019

\section{ABSTRACT}

A proportion of patients with interstitial lung diseases (ILDs), including the ILDs that are commonly associated with autoimmune diseases, develop a progressive fibrosing phenotype characterised by worsening of lung function, dyspnoea and quality of life, and early mortality. No drugs are approved for the treatment of ILDs other than idiopathic pulmonary fibrosis (IPF). At present, immunomodulatory medications are the mainstay of treatment for non-IPF ILDs. However, with the exception of systemic sclerosis-associated ILD, the evidence to suggest that immunosuppression may preserve lung function in patients with these ILDs comes only from retrospective, observational, or uncontrolled studies. In this article, we review the

Enhanced Digital Features To view enhanced digital features for this article go to https://doi.org/10.6084/ m9.figshare.8109308.

T. M. Maher

NIHR Clinical Research Facility Royal Brompton

Hospital, London, UK

T. M. Maher $(\varangle)$

National Heart and Lung Institute, Imperial College

London, London, UK

e-mail: t.maher@imperial.ac.uk

W. Wuyts

Unit for Interstitial Lung Diseases, Department of Respiratory Diseases, University Hospitals Leuven, Leuven, Belgium evidence for the treatments currently used to treat ILDs associated with autoimmune diseases and other ILDs and the ongoing trials of immunosuppressant and antifibrotic therapies in patients with these ILDs.

Funding: Boehringer Ingelheim.

Keywords: Collagen diseases; Immunosuppression; Interstitial lung disease; Respiratory; Rheumatic diseases; Treatment

\section{INTRODUCTION}

Interstitial lung disease (ILD) encompasses a large and heterogeneous group of parenchymal lung disorders, which may be related to systemic diseases or environmental exposures or have no known cause. Some individuals with certain types of fibrosing ILD develop a progressive phenotype characterised by worsening of lung function, dyspnoea and quality of life, and early mortality [1]. Idiopathic pulmonary fibrosis (IPF), an ILD of unknown cause that predominantly affects older adults [2], is invariably progressive and is associated with a median survival of only 3-4 years [3, 4]. A progressive fibrosing phenotype has also been observed to develop in a proportion of patients with other ILDs, including ILD associated with rheumatoid arthritis (RA-ILD) [5], systemic sclerosis (SScILD) [6], polymyositis/dermatomyositis [7], 
chronic sarcoidosis [8], chronic hypersensitivity pneumonitis (cHP) [9], idiopathic non-specific interstitial pneumonia (iNSIP) [10] and unclassifiable ILD [11]. Irrespective of the trigger for the lung injury, progressive fibrosing ILDs show commonalities not only in disease behaviour but also in the pathogenic mechanisms that drive the fibrotic process, which culminate in irreversible loss of epithelial or endothelial barrier integrity, destruction of the lung architecture and loss of lung function [12].

No drugs are approved for the treatment of ILDs other than nintedanib and pirfenidone for IPF. No treatment guidelines have been issued by an international professional association for forms of ILD other than IPF $[13,14]$ and SSc-ILD $[15,16]$ and there is a paucity of scientific evidence to guide therapeutic decision-making even in SSc-ILD $[17,18]$. Immunosuppression is the mainstay of therapy for all fibrosing ILDs other than IPF, but its efficacy and safety in the treatment of these ILDs have not been established. Of concern to many is that immunosuppression was also the "gold standard" approach to the treatment of IPF until the results of the PANTHER-IPF trial showed that combination therapy with prednisone, azathioprine and $\mathrm{N}$-acetylcysteine (but not $\mathrm{N}$-acetylcysteine alone) was associated with an increased risk of hospitalisations and death in this patient population $[19,20]$. In this article, we review the evidence for the treatments currently used to treat ILDs that may be associated with a progressive fibrosing phenotype.

This review article is based on previously conducted studies and does not contain any studies with human participants or animals performed by either of the authors.

\section{CORTICOSTEROIDS}

Corticosteroids are widely used as first-line therapy for ILDs other than IPF [21], but there is very little evidence to support their efficacy in treating ILD. International guidelines for the treatment of IPF provide a strong recommendation against the use of corticosteroid monotherapy other than in the treatment of acute exacerbations [13]. Among nearly 4000 patients with SSc-ILD recorded in the EUSTAR database between 2004 and 2014, glucocorticoids had been taken by $59 \%$ of patients at some point, but it is unclear what percentage of these patients were given corticosteroids with the intention to treat ILD [22]. Glucocorticoids are recommended for patients with RA if the disease remains active after treatment with disease-modifying drugs or biologics [23], but there is no evidence that glucocorticoids ameliorate RA-ILD. Corticosteroids are an established treatment for pulmonary sarcoidosis: in a Delphi consensus study, 92\% of experts indicated that corticosteroids were the preferred first-line treatment [24]. There is very little evidence to support the efficacy of corticosteroids in patients with cHP. Only one randomised placebo-controlled trial has been published, which was small $(n=36)$ and short (8 weeks) [25]. A retrospective study of medical records from all patients with HP followed at a single centre between 2005 and 2016 found that although patients with non-fibrotic disease $(n=93)$ showed an improvement in lung function following initiation of corticosteroids, no benefit was observed in patients with fibrotic disease $(n=109)$, in whom median survival was only 9.2 years [26]. There is some evidence that corticosteroids may be beneficial in the treatment of iNSIP. In an analysis of 86 patients with iNSIP treated with corticosteroids (with or without other immunosuppressants) and followed for at least 1 year, nearly half had an improvement in forced vital capacity (FVC) of at least 10\% predicted. This response appeared to be associated with lower pulmonary function at baseline, a shorter duration of respiratory symptoms, and negativity for anti-nuclear antibody [27]. It should be noted that long-term use of corticosteroids is associated with substantial morbidity, including weight gain, diabetes, cardiovascular events, cataracts and osteoporosis [28]. Decisions on whether to use, or continue to use, corticosteroids in patients with ILDs should be individualized to the patient and take into account the patient's clinical condition, including comorbidities, and the occurrence of side effects. 


\section{CYCLOPHOSPHAMIDE (CYC)}

CYC is an immunosuppressant that may be delivered orally or intravenously. The latest guidelines for treatment of SSc-ILD, issued by the European League Against Rheumatism Collaborative Initiative (EULAR) in 2016, recommend the use of tailored CYC therapy, in particular for patients with progressive disease [16]. In algorithms for the treatment of SSc-ILD developed in 2016-2017, the consensus of experts was that intravenous CYC should be used as second-line induction therapy, after mycophenolate mofetil (MMF) [18]. The efficacy and safety of CYC in patients with SSc-ILD were investigated in two randomised placebo-controlled trials: the Fibrosing Alveolitis in Scleroderma Trial (FAST) and Scleroderma Lung Study I (SLS I). In FAST, in which 158 subjects were randomised to receive lowdose prednisolone plus intravenous CYC for 6 months followed by oral azathioprine for 6 months, or placebo for 1 year, there was an improvement of $2.4 \%$ in FVC \% predicted with active treatment versus a decline of $3.0 \%$ with placebo [29]. In SLS I, the mean decline from baseline in $\mathrm{FVC} \%$ predicted at 1 year was $1.0 \%$ in subjects treated with oral CYC versus $2.6 \%$ in those treated with placebo [30]. CYC is associated with side effects related to immunosuppression, such as leucopenia, haematuria and neutropenia [30], limiting its use as a long-term treatment.

FAST and SLS I are the only randomised controlled trials of CYC conducted in patients with ILDs. The use of CYC in ILDs other than SSc-ILD has been investigated only in small retrospective or uncontrolled studies. In a retrospective study of 21 patients with progressive RA-ILD, survival time was greater (72 versus 43 months) in patients treated with CYC than in patients with better baseline lung function who did not receive CYC [31]. In a retrospective analysis of 307 patients with severe ILDs, including autoimmune ILDs (37\%), unclassifiable ILD (20\%), and HP (19\%), intravenous CYC appeared to stabilize decline in lung function in the 6-12 months after treatment [32].

\section{AZATHIOPRINE}

The immunosuppressant azathioprine is widely used as second-line therapy for ILDs other than IPF [21]. In algorithms for the treatment of SScILD developed in 2016-2017, the consensus of experts was that azathioprine should be used as second-line maintenance therapy (after MMF) [18]. However, the only evidence to support the use of azathioprine in patients with SSc comes from uncontrolled open-label studies. In an open-label study in 13 patients with early diffuse SSc, of whom nine had lung involvement, patients treated with azathioprine for 1 year maintained mean FVC \% predicted and diffusing capacity of the lung for carbon monoxide $\left(\mathrm{DL}_{\mathrm{CO}} \%\right)$ predicted at the levels achieved following 1 year's treatment with intravenous CYC [33]. In an observational study of 18 months' treatment with oral azathioprine given after 6 months' treatment with intravenous CYC in 27 patients with SSc-ILD, 8 patients (30\%) had a change in FVC and/or total lung capacity (TLC) of less than $10 \%$ predicted and/or change in $\mathrm{DL}_{\mathrm{CO}}$ of less than $15 \%$ predicted, while $6(22 \%)$ had an increase in FVC and/or TLC greater than $10 \%$ predicted and/or increase in $\mathrm{DL}_{\mathrm{CO}}$ of greater than $15 \%$ predicted [34].

The evidence for the efficacy of azathioprine in other ILDs is also very limited. There is some evidence from uncontrolled open-label trials that azathioprine may stabilize lung function in patients with pulmonary sarcoidosis $[35,36]$. In a retrospective study of 55 patients with sarcoidosis who had not responded to, or had contraindications to, corticosteroids, forced expiratory volume in $1 \mathrm{~s}\left(\mathrm{FEV}_{1} \%\right)$ predicted, VC $\%$ predicted and $\mathrm{DL}_{\mathrm{CO}} \%$ predicted increased in those who completed 1 year of azathioprine (mean $\pm \mathrm{SD}$ increases of $10.0 \pm 14.5$, $7.8 \pm 14.7$ and $13.4 \pm 27.2$, respectively) [36]. In a retrospective analysis of 19 patients with cHP, treatment with azathioprine was associated with an improvement in $\mathrm{DL}_{\mathrm{CO}} \%$ predicted, but not FVC $\%$ predicted, after 1 year [37]. Adverse effects of azathioprine reported in patients with ILD include infections, gastrointestinal effects and elevated transaminases $[36,38]$. 


\section{METHOTREXATE}

Methotrexate is an immunosuppressant that may be delivered orally, or by intramuscular, subcutaneous, intravenous, or intrathecal injection. Methotrexate is recommended in EULAR guidelines as a treatment for skin manifestations in patients with early diffuse SSc [15] and is widely used in patients with SSc [22], but there is no evidence that it is effective in treating SSc-ILD. Methotrexate is approved for the treatment of RA, but has not been shown to ameliorate RA-ILD. It should also be noted that methotrexate has been reported as a rare cause of lung injury [39, 40]. Other adverse events associated with methotrexate include gastrointestinal disorders (e.g. stomatitis, dyspepsia, abdominal pain, nausea) and elevations in liver enzymes. Methotrexate was recommended as second-line therapy (after corticosteroids) by experts participating in a Delphi panel on the treatment of pulmonary sarcoidosis [24]. A retrospective analysis of patients with sarcoidosis who had not responded to, or had contraindications to, corticosteroids showed a mean \pm SD increase in $\mathrm{FEV}_{1} \%$ predicted, $\mathrm{VC} \%$ predicted and $\mathrm{DL}_{\mathrm{CO}} \%$ predicted of $7.6 \pm 14.4,9.2 \pm 13.1$ and $6.6 \pm 11.0$, respectively, in those who completed 1 year of methotrexate [36].

\section{MYCOPHENOLATE MOFETIL (MMF)}

MMF is an immunosuppressant that may be delivered orally or by intravenous infusion. In the randomised controlled SLS II, treatment with oral MMF for 2 years resulted in similar improvements in FVC as oral CYC for 1 year followed by placebo for 1 year (absolute changes of $2.88 \%$ predicted and $2.19 \%$, respectively; no significant difference between groups). MMF was better tolerated than CYC, with fewer premature withdrawals due to adverse events (35\% versus $42 \%$ ), fewer treatment-related serious adverse events ( $4 \%$ versus $10 \%$ ), and lower rates of leucopenia (41\% versus $6 \%$ ) and thrombocytopenia (6\% versus $0 \%$ ) [41]. No recommendation for or against the use of MMF was included in the treatment guidelines for SSc-ILD issued by EULAR in 2016 [16], which did not consider the results of SLS II. However, in algorithms developed by expert consensus in 2016-2017, the consensus of experts was that MMF should be used as first-line induction therapy and first-line maintenance therapy for SSc-ILD [18]. In a recent Delphi consensus study conducted in the USA, clinicians with expertise in managing SSc-ILD supported the use of MMF as first-line therapy for SSc-ILD [42].

No randomised controlled trials of MMF have been performed in ILDs other than SScILD, but there is some evidence from retrospective studies that MMF may have benefits on other ILDs. In a retrospective analysis of medical records from 125 patients with various connective tissue disease (CTD)-ILDs (including $35 \%$ with SSc-ILD, $26 \%$ with polymyositis/dermatomyositis-related ILD, $15 \%$ with lungdominant CTD, $14 \%$ with RA-ILD), treatment with MMF was associated with improvements in FVC $\%$ predicted of $4.9 \%, 6.1 \%$ and $7.3 \%$ at 1,2 and 3 years after initiation of MMF, and improvements in $\mathrm{DL}_{\mathrm{CO}} \%$ predicted of $6.3 \%$ and $7.1 \%$ after 1 and 2 years, respectively [43]. In a retrospective analysis of 51 patients with cHP, administration of MMF was associated with an improvement in $\mathrm{DL}_{\mathrm{CO}} \%$ predicted of $4.2 \%$, but no significant improvement in FVC \% predicted, after 1 year [37].

\section{RITUXIMAB}

Rituximab is an intravenous anti-CD20 monoclonal antibody that elicits immunosuppressant effects via depletion of peripheral B cells. It is approved for use in combination with methotrexate for the treatment of patients with severe active RA (in the EU) or moderately to severely active RA (in the USA) and an inadequate response to tumour necrosis factor- $\alpha$ antagonist therapy. While no randomised double-blind controlled trials of rituximab as a treatment for ILD have been completed, several retrospective or open-label studies have shown preservation or improvement in lung function in patients with CTD-ILDs treated with rituximab [44-51]. In an open-label study of 60 patients with SSc-ILD who were randomised to receive rituximab or CYC for 6 months, mean 
FVC improved from $61.3 \%$ to $67.5 \%$ predicted in the rituximab group compared with a decline from $59.3 \%$ to $58.1 \%$ predicted in the CYC group [49]. In a retrospective assessment of 50 patients with severe progressive ILD, there was a median improvement in FVC of $6.7 \%$ predicted after 6-12 months' treatment with rituximab compared with a median decline in FVC of $14.3 \%$ predicted in the previous $6-12$ months [46]. In an observational study of 56 patients with RA-ILD, the median relative change in FVC was $1.2 \%$ predicted in the $6-12$ months after initiation of rituximab compared with a decline of $2.4 \%$ predicted in the $6-12$ months before treatment [48]. In algorithms developed by expert consensus in 2016-2017, rituximab was recommended as third-line induction therapy (after MMF and CYC) for the treatment of SScILD [18]. Randomised double-blind controlled trials of rituximab in patients with ILDs are ongoing (Table 1).

\section{TOCILIZUMAB}

Tocilizumab is an interleukin-6 receptor antagonist with immunosuppressant and anti-inflammatory effects that is delivered via intravenous infusion or subcutaneous injection. Tocilizumab is approved for use in combination with methotrexate in the treatment of severe active RA, but has not been investigated as a treatment for RA-ILD. The efficacy and safety of tocilizumab in patients with SSc (but not necessarily SSc-ILD) have been investigated in two randomised controlled trials. In the faSScinate trial, there was no significant difference between tocilizumab and placebo on the primary endpoint, mean change from baseline in modified Rodnan skin score (mRSS) at week 24 , but an exploratory analysis of changes in FVC \% predicted suggested a potential benefit of tocilizumab on lung function [52]. Over 48 weeks, similar proportions of patients in each group withdrew because of an adverse event (14\% with tocilizumab versus $11 \%$ with placebo) but serious infections were more common with tocilizumab than placebo ( $16 \%$ versus $5 \%$, respectively) [52]. In the focuSSced trial, which involved 210 patients with SSc, there was no significant difference between tocilizumab and placebo on the primary endpoint of change in mRSS at week 48, but exploratory analyses of changes in FVC \% predicted suggested that tocilizumab may ameliorate loss of lung function. The mean change from baseline in FVC at week 48 was $-0.4 \%$ predicted in the tocilizumab group versus $-4.6 \%$ predicted in the placebo group, while the proportion of patients with an FVC decline of greater than 10\% predicted at week 48 was $5.4 \%$ versus $16.5 \%$ in these treatment groups, respectively [53].

\section{HAEMATOPOIETIC STEM CELL TRANSPLANTATION (HSCT)}

The latest guidelines issued by EULAR include a recommendation for use of autologous HSCT to treat patients with rapidly progressive SSc at risk of organ failure, but highlight that HSCT should only be performed after careful evaluation of the benefit and risks for the individual patient [16]. This recommendation was based on the results of two randomised trials: Autologous Stem Cell Transplantation International Scleroderma (ASTIS) and Scleroderma: Cyclophosphamide or Transplantation (SCOT). The ASTIS trial compared HSCT with CYC in patients with diffuse cutaneous SSc and renal, pulmonary or cardiac involvement. In the first 12 months, 8 of the 79 patients in the HSCT group and none of the 77 patients in the CYC group died from treatment-related causes. However, at month 12, HSCT was associated with significantly greater event-free survival than CYC (HR 0.52 [95\% CI 0.28, 0.96]). Significant improvements were observed with HSCT versus CYC in FVC \% predicted $(6.3 \%$ versus $-2.8 \%$ ) and total lung capacity $\%$ predicted $(5.1 \%$ versus $-1.3 \%)$ at month 24 . Grade 3 or 4 adverse events were reported by $63 \%$ and $37 \%$ of patients in the HSCT and CYC groups, respectively [54]. The SCOT trial compared HSCT with CYC in 75 subjects with diffuse cutaneous SSC and renal or pulmonary involvement. At month 72, event-free survival was greater with HSCT than CYC (74\% versus $47 \%$ ), as was overall survival ( $86 \%$ versus $51 \%$ ) [55]. In 2018, a task force of the American 
Table 1 Ongoing or recently completed randomised double-blind controlled trials of drugs in patients with fibrosing ILDs

\begin{tabular}{|c|c|c|c|c|}
\hline $\begin{array}{l}\text { ClinicalTrials.gov } \\
\text { identifier (trial } \\
\text { name) }\end{array}$ & Patient population & $\begin{array}{l}\text { Sample } \\
\text { size }\end{array}$ & $\begin{array}{l}\text { Drug under } \\
\text { investigation }\end{array}$ & Lung function endpoint $/ \mathrm{s}$ \\
\hline $\begin{array}{l}\text { NCT02597933 } \\
\quad\left(\text { SENSCIS }^{\circledR}\right) \\
{[90]}\end{array}$ & SSc-ILD & 576 & Nintedanib & $\begin{array}{l}\text { Rate of decline in FVC over } \\
52 \text { weeks ( } \mathrm{mL} / \text { year) (primary } \\
\text { endpoint) }\end{array}$ \\
\hline $\begin{array}{l}\text { NCT02999178 } \\
\quad\left(\text { INBUILD }^{\circledR}\right) \\
{[91]}\end{array}$ & $\begin{array}{l}\text { Progressive fibrosing ILDs other } \\
\text { than IPF }\end{array}$ & 663 & Nintedanib & $\begin{array}{l}\text { Rate of decline in FVC over } \\
52 \text { weeks (mL/year) (primary } \\
\text { endpoint) }\end{array}$ \\
\hline $\begin{array}{l}\text { NCT03099187 } \\
\quad[92]\end{array}$ & $\begin{array}{l}\text { Unclassifiable progressive fibrosing } \\
\text { ILD (with progression defined as } \\
\text { deterioration in FVC }>5 \% \text { or } \\
\text { significant symptomatic } \\
\text { worsening in last } 6 \text { months) }\end{array}$ & 252 & Pirfenidone & $\begin{array}{l}\text { Rate of decline in FVC }(\mathrm{mL}) \text { over } \\
24 \text { weeks (primary endpoint) }\end{array}$ \\
\hline $\begin{array}{l}\text { NCT02808871 } \\
\quad \text { (TRAIL1) }\end{array}$ & RA-ILD & $\approx 270$ & Pirfenidone & $\begin{array}{l}\text { Proportion of patients with decline } \\
\text { in FVC } \geq 10 \% \text { predicted or } \\
\text { death at week } 52 \text { (primary } \\
\text { endpoint) }\end{array}$ \\
\hline $\begin{array}{l}\text { NCT03221257 } \\
\quad(\text { SLS III) }\end{array}$ & SSc-ILD & $\approx 150$ & $\begin{array}{l}\text { Pirfenidone } \\
\text { plus MMF } \\
\text { (vs MMF } \\
\text { alone) }\end{array}$ & $\begin{array}{l}\text { Change in FVC \% predicted at } \\
\text { month } 18 \text { (primary endpoint) }\end{array}$ \\
\hline $\begin{array}{l}\text { NCT03260556 } \\
\text { (PirFS) }\end{array}$ & Progressive fibrotic sarcoidosis & $\approx 60$ & Pirfenidone & $\begin{array}{l}\text { Change in FVC at month } 48 \\
\text { (secondary endpoint) }\end{array}$ \\
\hline NCT02958917 & $\begin{array}{l}\text { Fibrotic HP (with no evidence of } \\
\text { improvement in disease severity } \\
\text { over preceding year) }\end{array}$ & $\approx 40$ & Pirfenidone & $\begin{array}{l}\text { Change in FVC \% predicted from } \\
\text { baseline at week } 52 \text { (primary } \\
\text { endpoint) }\end{array}$ \\
\hline $\begin{array}{c}\text { NCT02990286 } \\
\text { (EvER-ILD) }\end{array}$ & $\begin{array}{l}\text { CTD-ILD or IPAF or idiopathic } \\
\text { ILD, plus NSIP based on HRCT } \\
\text { or histology, plus lack of response } \\
\text { to immunosuppressant therapy } \\
\text { for ILD }\end{array}$ & $\approx 122$ & $\begin{array}{l}\text { Rituximab } \\
\text { plus MMF } \\
\text { (vs MMF } \\
\text { alone) }\end{array}$ & $\begin{array}{l}\text { Change in FVC \% predicted from } \\
\text { baseline at week } 24 \text { (primary } \\
\text { endpoint) and change in } \mathrm{DL}_{\mathrm{CO}} \\
\text { from baseline at week } 24 \\
\text { (secondary endpoint) }\end{array}$ \\
\hline $\begin{array}{l}\text { NCT01862926 } \\
\text { (RECITAL) [93] }\end{array}$ & $\begin{array}{l}\text { Severe and/or progressive ILD } \\
\text { associated with SSc, idiopathic } \\
\text { inflammatory myositis (including } \\
\text { anti-synthetase syndrome), or } \\
\text { MCTD }\end{array}$ & $\approx 116$ & $\begin{array}{l}\text { Rituximab vs } \\
\text { IV CYC }\end{array}$ & $\begin{array}{l}\text { Changes in FVC }(\mathrm{mL}) \text { from } \\
\text { baseline at week } 24 \text { (primary } \\
\text { endpoint) and } 48 \text { (secondary } \\
\text { endpoint) }\end{array}$ \\
\hline
\end{tabular}

As per ClinicalTrials.gov on 29 April 2019. Comparator is placebo unless otherwise stated CTD-ILD connective tissue disease-associated ILD, IPAF interstitial pneumonia with autoimmune features, MCTD mixed connective tissue disease, NSIP non-specific interstitial pneumonia 
Society for Blood and Marrow Transplantation recommended autologous HSCT as standard of care for patients with severe SSc, with close collaboration between expert rheumatologists and transplant physicians to identify eligible patients [56].

\section{LUNG TRANSPLANTATION}

Given its very poor prognosis, lung transplantation should be considered for patients with IPF at an early stage of disease [13, 57]. Lung transplantation should also be considered for patients with severe autoimmune ILDs who have not responded to treatment and have no contraindications [57], but the prevalence of contraindications means that only a minority of patients are eligible. Many patients with SSc-ILD are not referred for transplant because of concerns that oesophageal dysmotility and gastroparesis may increase the risk of aspiration and transplant rejection. However, successful transplantation is possible in carefully selected patients with SSc-ILD. In a retrospective analysis of data from a single US centre, survival after lung transplant in 72 patients with SSc referred between 2005 and 2013 was $81 \%$ at 1 year and $66 \%$ at 5 years [58]. Post-transplant survival rates of $93 \%, 76 \%$, and $60 \%$ after 1,3 , and 5 years were reported in a retrospective analysis of 30 patients with SSc-ILD who underwent lung or heart-lung transplant at 14 centres between 1993 and 2016 [59]. Data on posttransplant survival in patients with other ILDs are limited to small short-term studies [60-62]. In an analysis of five patients with ILD associated with idiopathic inflammatory myopathy, all patients survived for 1 year after transplant. Among a cohort of 37 patients with non-IPF ILDs (14 with HP, 9 with RA, 6 with SSc, 3 with systemic lupus erythematosus), the 1-, 2- and 5 -year survival rates after lung transplant were $86 \%, 63 \%$ and $57 \%$ [61]. A recent analysis of 15 patients with autoimmune ILDs (5 with polymyositis/dermatomyositis, 4 with RA, 3 with SSc) who underwent lung transplant at a Korean centre showed a 1-year survival rate of $80 \%$ [62].

\section{ANTIFIBROTIC THERAPIES}

Fibrosing ILDs show commonalities in pathogenic pathways [63]. Some ILDs, such as those related to CTDs, are initially inflammatory disorders, in which endothelial injury triggers an excessive fibro-proliferative response under certain conditions. Other ILDs are primarily fibro-proliferative disorders in which fibrosis results from pathological alterations to the lung epithelium [64-66]. In progressive fibrosing ILDs, repetitive injuries at epithelial or endothelial sites lead to cell destruction and unregulated repair. Fibroblasts orchestrated to the site of injury are activated to become myofibroblasts, which secrete excessive amounts of extracellular matrix, resulting in increased tissue stiffness, which further activates and stimulates fibroblasts [64, 67, 68]. Macrophages and lymphocytes recruited to the site of injury release pro-fibrotic mediators, such as transforming growth factor $\beta 1$, connective tissue growth factor and platelet-derived growth factor [68]. These processes result in a self-sustaining and progressive process of fibrosis. It has been postulated that, irrespective of the initial injury, once fibrosis has become progressive, a therapy that acts on fibrotic pathways is required to slow disease progression. This provides a rationale for investigating the drugs known to slow disease progression in patients with IPF-pirfenidone and nintedanib-as treatments for other forms of fibrosing ILD.

In patients with IPF, pirfenidone reduces lung function decline with a side effect profile characterised mainly by gastrointestinal events and rash [69]. The open-label LOTUSS study suggested that pirfenidone also had an acceptable safety and tolerability profile in subjects with SSc-ILD, but no conclusions could be drawn about its effects on lung function because of the lack of a comparator group [70]. The efficacy and safety of pirfenidone in subjects with SSc-ILD (in combination with MMF versus MMF alone), unclassifiable progressive fibrosing ILD, RA-ILD, fibrotic sarcoidosis and fibrotic HP are currently being investigated in clinical trials (Table 1 ). 
Nintedanib has been shown to slow lung function decline and reduce the risk of acute exacerbations in patients with IPF, with side effects that are mainly gastrointestinal [71, 72]. Nintedanib is an intracellular inhibitor of tyrosine kinases, which blocks processes fundamental to the pathogenesis of fibrosis, including the proliferation, migration and differentiation of fibroblasts, the deposition of extracellular matrix and the release of pro-fibrotic mediators [73, 74]. Nintedanib has demonstrated antifibrotic and anti-inflammatory effects in animal models resembling aspects of fibrosing ILDs, including those with an immunological trigger [73, 75-79]. The efficacy and safety of nintedanib in subjects with SScILD and in subjects with progressive fibrosing ILDs other than IPF have been investigated in the SENSCIS ${ }^{\circledR}$ and INBUILD ${ }^{\circledR}$ trials, respectively (Table 1). The primary endpoint in both these trials is the annual rate of decline in FVC $(\mathrm{mL} /$ year) assessed over 52 weeks.

\section{CHOICE OF TREATMENT}

Clearly the first step in selecting an appropriate treatment for a patient with ILD is to ensure that they have received the correct diagnosis. Multidisciplinary team discussion to integrate clinical, radiological and laboratory data is the gold standard for making a differential diagnosis of ILD [80]. In the absence of adequate scientific evidence to guide treatment decisions for patients with fibrosing ILDs other than IPF, clinicians must rely on the limited data available, expert opinion and their clinical experience. Some treatment options, based on our clinical experience and recommendations published by experts in the field, are shown in Table 2. Other than nintedanib and pirfenidone for the treatment of IPF, none of these therapies is approved for the treatment of ILD, nor supported by a robust evidence base. Not all patients with ILD require drug treatment. In some patients, it may be appropriate not to initiate therapy but to ensure that patients are closely monitored for disease progression. However, patients with progressive disease warrant consideration of drug therapy. All patients with IPF, which is invariably progressive and has a very poor prognosis, should be offered treatment with nintedanib or pirfenidone to slow the progression of their disease.

\section{OVERALL CARE OF PATIENTS WITH FIBROSING ILDS}

All patients with fibrosing ILDs should receive supportive care. Measures to alleviate symptoms and preserve quality of life should be initiated early and tailored to the needs of the patient [81]. Pulmonary rehabilitation or exercise training can improve exercise capacity and quality of life in patients with ILDs, particularly if started when the patient's physiology is less impaired [82, 83]. The use of supplementary oxygen in patients with ILD and hypoxia can help to alleviate dyspnoea and improve quality of life [84]. Vaccines should be recommended to reduce the risk of respiratory infections. Prophylactic antibiotics may also be considered to reduce the risk of infections and associated hospitalisations [85]. For patients with HP, a thorough investigation for the inciting antigen should be performed and, if the antigen can be identified, the patient advised of the importance of antigen avoidance [86]. Management of extra-pulmonary manifestations of disease and identification and treatment of comorbidities can improve patient outcomes [87-89].

\section{CONCLUSIONS}

There is a lack of robust evidence to guide the management of patients with fibrosing ILDs other than IPF. Immunomodulatory medications are the mainstay of treatment, but there is very limited evidence to support their efficacy or safety as treatments for ILDs other than SScILD. Progressive fibrosing ILDs show commonalities in underlying pathogenetic mechanisms, suggesting that drugs that slow the progression of IPF may also have utility in slowing the progression of other progressive fibrosing ILDs. Ongoing trials will provide valuable insights into the potential use of immunomodulatory 
Table 2 Pharmacological treatment options for ILDs

\begin{tabular}{|c|c|}
\hline Type of ILD & Treatment options \\
\hline IPF & Nintedanib or pirfenidone \\
\hline \multirow[t]{7}{*}{ SSc-ILD } & Induction therapy: \\
\hline & 1st line: MMF or cyclophosphamide \\
\hline & 2nd line: MMF or cyclophosphamide \\
\hline & 3rd line: rituximab \\
\hline & Maintenance therapy: \\
\hline & 1st line: $\mathrm{MMF}$ \\
\hline & 2nd line: azathioprine \\
\hline \multirow[t]{2}{*}{ RA-ILD } & Rituximab \\
\hline & MMF or cyclophosphamide (in combination with therapy to treat articular manifestations) \\
\hline \multirow{4}{*}{$\begin{array}{l}\text { ILD associated with } \\
\text { polymyositis/ } \\
\text { dermatomyositis }\end{array}$} & Induction therapy: \\
\hline & 1st line: high-dose corticosteroids with oral taper \\
\hline & 2nd line: rituximab or cyclophosphamide \\
\hline & Maintenance therapy: mycophenolate or azathioprine \\
\hline \multirow[t]{2}{*}{ MCTD-ILD } & If dominant histopathologic subtype is NSIP or UIP, treat as per SSc-ILD \\
\hline & $\begin{array}{l}\text { If dominant histopathologic subtype is OP, treat as per ILD associated with } \\
\text { polymyositis/dermatomyositis }\end{array}$ \\
\hline \multirow[t]{2}{*}{ IPAF } & If dominant histopathologic subtype is NSIP or UIP, treat as per SSc-ILD \\
\hline & $\begin{array}{l}\text { If dominant histopathologic subtype is OP, treat as per ILD associated with } \\
\text { polymyositis/dermatomyositis }\end{array}$ \\
\hline $\begin{array}{l}\text { Hypersensitivity } \\
\text { pneumonitis }^{\mathrm{a}}\end{array}$ & $\begin{array}{l}\text { Patients with signs of inflammation: trial of immunosuppression (corticosteroids tapered to low } \\
\text { dose } \pm \text { cytotoxic agent) }\end{array}$ \\
\hline \multirow[t]{4}{*}{ Pulmonary sarcoidosis } & 1st line: corticosteroids \\
\hline & 2nd line: methotrexate, azathioprine \\
\hline & 3rd line: infliximab, leflunomide, hydroxychloroquine \\
\hline & 4th line: thalidomide \\
\hline Unclassifiable ILD & $\begin{array}{l}\text { Treat according to working diagnosis but undertake regular reassessment and refine diagnosis } \\
\text { according to treatment response and/or the emergence of new symptoms, clinical signs or } \\
\text { radiological features }\end{array}$ \\
\hline
\end{tabular}

Nintedanib and pirfenidone are approved for the treatment of IPF. Other than these, none of the drugs shown in this table is approved for the treatment of any ILD

$I P A F$ interstitial pneumonia with autoimmune features, $I P F$ idiopathic pulmonary fibrosis, $M C T D$ mixed connective tissue disease, $M M F$ mycophenolate mofetil, NSIP non-specific interstitial pneumonia, $O P$ organising pneumonia, $R A-I L D$ rheumatoid arthritis-associated ILD, UIP usual interstitial pneumonia

${ }^{a}$ In addition to drug therapy, avoidance of exposure to the inciting antigen where it can be identified is a key element of the management of hypersensitivity pneumonitis 
and antifibrotic agents in the management of fibrosing ILDs with a progressive phenotype.

\section{ACKNOWLEDGEMENTS}

Funding. The article processing charges and Open Access fee were funded by Boehringer Ingelheim. The authors were fully responsible for all content and editorial decisions, were involved at all stages of development and have approved the final version.

Medical Writing Assistance. Medical writing assistance, supported financially by Boehringer Ingelheim, was provided by Elizabeth $\mathrm{Ng}$ and Wendy Morris of FleishmanHillard Fishburn, London, UK during preparation of this manuscript.

Authorship. All named authors meet the International Committee of Medical Journal Editors (ICMJE) criteria for authorship for this article, take responsibility for the integrity of the work as a whole, and have given their approval for this version to be published.

Disclosures. Outside the submitted work, Toby M Maher reports receiving grant funding to his institution and personal fees for service on a clinical trial advisory board from GlaxoSmithKline; personal fees from Boehringer Ingelheim, InterMune/Roche, Sanofi Aventis, AstraZeneca, Biogen Idec, Cipla, Prometic and Sanumed; research fees to his institution; personal fees and non-financial support from UCB; he holds stock options in Apellis. Outside the submitted work, Wim Wuyts reports receiving grant funding to his institution from Boehringer Ingelheim and Roche.

Compliance with Ethics Guidelines. This review article is based on previously conducted studies and does not contain any studies with human participants or animals performed by any of the authors.
Data Availability. Data sharing is not applicable to this article as no datasets were generated or analysed during the current study.

Open Access. This article is distributed under the terms of the Creative Commons Attribution-NonCommercial 4.0 International License (http://creativecommons.org/licenses/ by-nc/4.0/), which permits any noncommercial use, distribution, and reproduction in any medium, provided you give appropriate credit to the original author(s) and the source, provide a link to the Creative Commons license, and indicate if changes were made.

\section{REFERENCES}

1. Kolb M, Vašáková $M$. The natural history of progressive fibrosing interstitial lung diseases. Respir Res. 2019;20(1):57.

2. Raghu G, Remy-Jardin M, Myers JL, et al. Diagnosis of idiopathic pulmonary fibrosis. An official ATS/ ERS/JRS/ALAT clinical practice guideline. Am J Respir Crit Care Med. 2018;198:e44-68.

3. Raghu G, Chen SY, Yeh WS, et al. Idiopathic pulmonary fibrosis in US Medicare beneficiaries aged 65 years and older: incidence, prevalence, and survival, 2001-11. Lancet Respir Med. 2014;2:566-72.

4. Strongman H, Kausar I, Maher TM. Incidence, prevalence, and survival of patients with idiopathic pulmonary fibrosis in the UK. Adv Ther. 2018;35:724-36.

5. Zamora-Legoff JA, Krause ML, Crowson CS, et al. Progressive decline of lung function in rheumatoid arthritis-associated interstitial lung disease. Arthritis Rheumatol. 2017;69:542-9.

6. Guler SA, Winstone TA, Murphy D, et al. Does systemic sclerosis-associated interstitial lung disease burn out? Specific phenotypes of disease progression. Ann Am Thorac Soc. 2018;15:1427-33.

7. Marie I, Hatron PY, Dominique S, et al. Short-term and long-term outcomes of interstitial lung disease in polymyositis and dermatomyositis: a series of 107 patients. Arthritis Rheum. 2011;63:3439-47.

8. Patterson KC, Strek ME. Pulmonary fibrosis in sarcoidosis. Clinical features and outcomes. Ann Am Thorac Soc. 2013;10:362-70. 
9. Fernández Pérez ER, Swigris JJ, Forssén AV, et al. Identifying an inciting antigen is associated with improved survival in patients with chronic hypersensitivity pneumonitis. Chest. 2013;144:1644-51.

10. Belloli EA, Beckford R, Hadley R, et al. Idiopathic non-specific interstitial pneumonia. Respirology. 2016;21:259-68.

11. Guler SA, Ellison K, Algamdi M, et al. Heterogeneity in unclassifiable interstitial lung disease. A systematic review and meta-analysis. Ann Am Thorac Soc. 2018;15:854-63.

12. Wuyts WA, Agostini C, Antoniou KM, et al. The pathogenesis of pulmonary fibrosis: a moving target. Eur Respir J. 2013;41:1207-18.

13. Raghu G, Collard HR, Egan JJ, et al. An official ATS/ ERS/JRS/ALAT statement: idiopathic pulmonary fibrosis: evidence-based guidelines for diagnosis and management. Am J Respir Crit Care Med. 2011;183:788-824.

14. Raghu G, Rochwerg B, Zhang Y, et al. An official ATS/ERS/JRS/ALAT clinical practice guideline: treatment of idiopathic pulmonary fibrosis. An update of the 2011 clinical practice guideline. Am J Respir Crit Care Med. 2015;192:e3-19.

15. Kowal-Bielecka O, Landewé R, Avouac J, et al. EULAR recommendations for the treatment of systemic sclerosis: a report from the EULAR Scleroderma Trials and Research group (EUSTAR). Ann Rheum Dis. 2009;68:620-8.

16. Kowal-Bielecka O, Fransen J, Avouac J, et al. Update of EULAR recommendations for the treatment of systemic sclerosis. Ann Rheum Dis. 2017;76:1327-39.

17. Hoffmann-Vold A, Maher T, Philpot E, et al. Assessment of recent evidence to support treatment recommendations in patients with SSc-ILD. Arthritis Rheumatol. 2018;70(suppl 10). https:// acrabstracts.org/abstract/assessment-of-recent-evid ence-to-support-treatment-recommendations-in-pa tients-with-ssc-ild/. Accessed 18 Sept 2018.

18. Fernández-Codina A, Walker KM, Pope JE. Treatment algorithms for systemic sclerosis according to experts. Arthritis Rheumatol. 2018;70:1820-8.

19. Idiopathic Pulmonary Fibrosis Clinical Research Network, Raghu G, Anstrom KJ, et al. Prednisone, azathioprine, and $\mathrm{N}$-acetylcysteine for pulmonary fibrosis. N Engl J Med. 2012;366:1968-77.

20. Idiopathic Pulmonary Fibrosis Clinical Research Network, Martinez FJ, De Andrade JA, et al. Randomized trial of acetylcysteine in idiopathic pulmonary fibrosis. N Engl J Med. 2014;370:2093-101.
21. Kreuter M, Olson A, Fischer A, et al. Current treatment of patients with non-IPF progressive fibrosing interstitial lung diseases. In: Poster presented at the American Thoracic Society (ATS) international conference, San Diego, May 2018.

22. Adler S, Huscher D, Siegert E, et al. Systemic sclerosis associated interstitial lung disease-individualized immunosuppressive therapy and course of lung function: results of the EUSTAR group. Arthritis Res Ther. 2018;20:17.

23. Singh JA, Saag KG, Bridges SL Jr, et al. 2015 American College of Rheumatology guideline for the treatment of rheumatoid arthritis. Arthritis Care Res (Hoboken). 2016;68:1-25.

24. Schutt AC, Bullington WM, Judson MA. Pharmacotherapy for pulmonary sarcoidosis: a Delphi consensus study. Respir Med. 2010;104:717-23.

25. Kokkarinen JI, Tukiainen HO, Terho EO. Effect of corticosteroid treatment on the recovery of pulmonary function in farmer's lung. Am Rev Respir Dis. 1992;145:3-5.

26. De Sadeleer LJ, Hermans F, De Dycker E, et al. Effects of corticosteroid treatment and antigen avoidance in a large hypersensitivity pneumonitis cohort: a single-centre cohort study. J Clin Med. 2018;8(1):14.

27. Lee SH, Park MS, Kim SY, et al. Factors affecting treatment outcome in patients with idiopathic nonspecific interstitial pneumonia: a nationwide cohort study. Respir Res. 2017;18:204.

28. Oray M, Abu Samra K, Ebrahimiadib N, et al. Longterm side effects of glucocorticoids. Expert Opin Drug Saf. 2016;15:457-65.

29. Hoyles RK, Ellis RW, Wellsbury J, et al. A multicenter, prospective, randomized, double-blind, placebo-controlled trial of corticosteroids and intravenous cyclophosphamide followed by oral azathioprine for the treatment of pulmonary fibrosis in scleroderma. Arthritis Rheum. 2006;54:3962-70.

30. Tashkin DP, Elashoff R, Clements PJ, et al. Cyclophosphamide versus placebo in scleroderma lung disease. N Engl J Med. 2006;354:2655-66.

31. Kelly C, Palmer E, Gordon J, et al. Pulsed cyclophosphamide in the treatment of rheumatoid arthritis-related interstitial lung disease (RA-ILD). Ann Rheum Dis. 2014;73:74.

32. Saunders $\mathrm{P}$, Sharma S, Kokosi M, et al. Intravenous cyclophosphamide as a treatment for severe interstitial lung disease. Am J Respir Crit Care Med. 2017;195:A1544. 
33. Paone C, Chiarolanza I, Cuomo G, et al. Twelvemonth azathioprine as maintenance therapy in early diffuse systemic sclerosis patients treated for 1-year with low dose cyclophosphamide pulse therapy. Clin Exp Rheumatol. 2007;25:613-6.

34. Bérezné A, Ranque B, Valeyre D, et al. Therapeutic strategy combining intravenous cyclophosphamide followed by oral azathioprine to treat worsening interstitial lung disease associated with systemic sclerosis: a retrospective multicenter open-label study. J Rheumatol. 2008;35:1064-72.

35. Müller-Quernheim J, Kienast K, Held M, et al. Treatment of chronic sarcoidosis with an azathioprine/prednisolone regimen. Eur Respir J. 1999;14:1117-22.

36. Vorselaars ADM, Wuyts WA, Vorselaars VMM, et al. Methotrexate vs azathioprine in second-line therapy of sarcoidosis. Chest. 2013;144:805-12.

37. Morisset J, Johannson KA, Vittinghoff E, et al. Use of mycophenolate mofetil or azathioprine for the management of chronic hypersensitivity pneumonitis. Chest. 2017;151:619-25.

38. Oldham JM, Lee C, Valenzi E, et al. Azathioprine response in patients with fibrotic connective tissue disease-associated interstitial lung disease. Respir Med. 2016;121:117-22.

39. Arakawa H, Yamasaki M, Kurihara $Y$, et al. Methotrexate-induced pulmonary injury: serial CT findings. J Thorac Imaging. 2003;18:231-6.

40. Camus P. The drug-induced respiratory disease website: methotrexate. In: Pneumotox online v2.2. https://www.pneumotox.com/drug/view/201/metho trexate. Accessed 18 Sept 2018.

41. Tashkin DP, Roth MD, Clements PJ, et al. Mycophenolate mofetil versus oral cyclophosphamide in scleroderma-related interstitial lung disease (SLS II): a randomised controlled, doubleblind, parallel group trial. Lancet Respir Med. 2016;4:708-19.

42. Rahaghi FF, Strek ME, Southern BD, et al. Expert consensus on the screening, treatment, and management of patients with SSc-ILD, and the potential future role of anti-fibrotics in a treatment paradigm for SSc-ILD: a Delphi consensus study. In: Poster to be presented at the American Thoracic Society (ATS) international conference, May 2019, Dallas, USA.

43. Fischer A, Brown KK, Du Bois RM, et al. Mycophenolate mofetil improves lung function in connective tissue disease-associated interstitial lung disease. J Rheumatol. 2013;40:640-6.
44. Daoussis D, Liossis SN, Tsamandas AC, et al. Experience with rituximab in scleroderma: results from a 1-year, proof-of-principle study. Rheumatology (Oxford). 2010;49:271-80.

45. Keir JG, Maher TM, Hansell DM, et al. Severe interstitial lung disease in connective tissue disease: rituximab as rescue therapy. Eur Respir J. 2012;40:641-6.

46. Keir GJ, Maher TM, Ming D, et al. Rituximab in severe, treatment-refractory interstitial lung disease. Respirology. 2014;19:353-9.

47. Lepri G, Avouac J, Airo P, et al. Effects of rituximab in connective tissue disorders related interstitial lung disease. Clin Exp Rheumatol. 2016;34:181-5.

48. Md Yusof MY, Kabia A, Darby M, et al. Effect of rituximab on the progression of rheumatoid arthritis-related interstitial lung disease: 10 years' experience at a single centre. Rheumatology (Oxford). 2017;56:1348-57.

49. Sircar G, Goswami RP, Sircar D, et al. Intravenous cyclophosphamide vs rituximab for the treatment of early diffuse scleroderma lung disease: open label, randomized, controlled trial. Rheumatology (Oxford). 2018;57:2106-13.

50. Doyle TJ, Dhillon N, Madan R, et al. Rituximab in the treatment of interstitial lung disease associated with antisynthetase syndrome: a multicenter retrospective case review. J Rheumatol. 2018;45: 841-50.

51. Narvaez FJ, Robles Perez A, Luburich P, et al. Efficacy and safety in the middle-long period of rituximab in the treatment of diffuse interstitial pulmonary disease associated with rheumatoid arthritis. Arthritis Rheumatol. 2018;70(suppl 10). https://acrabstracts.org/abstract/efficacy-and-safetyin-the-middle-long-period-of-rituximab-in-the-treat ment-of-diffuse-interstitial-pulmonary-disease-asso ciated-with-rheumatoid-arthritis/. Accessed 18 Sept 2018.

52. Khanna D, Denton CP, Jahreis A, et al. Safety and efficacy of subcutaneous tocilizumab in adults with systemic sclerosis (faSScinate): a phase 2, randomised, controlled trial. Lancet. 2016;387:263040.

53. Khanna D, Lin CJF, Kuwana M, et al. Efficacy and safety of tocilizumab for the treatment of systemic sclerosis: results from a phase 3 randomized controlled trial. In: Oral presentation at the American College of Rheumatology (ACR)/Association of Rheumatology Professionals (ARHP) annual meeting 2018, Chicago, USA. 
54. Van Laar JM, Farge D, Sont JK, et al. Autologous hematopoietic stem cell transplantation vs intravenous pulse cyclophosphamide in diffuse cutaneous systemic sclerosis. A randomized trial. JAMA. 2014;311:2490-8.

55. Sullivan KM, Goldmuntz EA, Keyes-Elstein L, et al. Myeloablative autologous stem-cell transplantation for severe scleroderma. N Engl J Med. 2018;378:35-47.

56. Sullivan KM, Majhail NS, Bredeson C, et al. Systemic sclerosis as an indication for autologous hematopoietic cell transplantation: position statement from the American Society for Blood and Marrow Transplantation. Biol Blood Marrow Transplant. 2018;24(10):1961-4.

57. Weill D, Benden C, Corris PA, et al. A consensus document for the selection of lung transplant candidates: 2014-an update from the Pulmonary Transplantation Council of the International Society for Heart and Lung Transplantation. J Heart Lung Transplant. 2015;34:1-15.

58. Crespo MM, Bermudez CA, Dew MA, et al. Lung transplant in patients with scleroderma compared with pulmonary fibrosis. Short- and long-term outcomes. Ann Am Thorac Soc. 2016;13:84-92.

59. Pradère $P$, Tudorache I, Magnusson J, et al. Lung transplantation for scleroderma lung disease: an international, multicenter, observational cohort study. J Heart Lung Transplant. 2018;37:903-11.

60. Yazdani A, Singer LG, Strand V, et al. Survival and quality of life in rheumatoid arthritis-associated interstitial lung disease after lung transplantation. J Heart Lung Transplant. 2014;33:514-20.

61. Ameye $\mathrm{H}$, Ruttens $\mathrm{D}$, Benveniste $\mathrm{O}$, et al. Is lung transplantation a valuable therapeutic option for patients with pulmonary polymyositis? Experiences from the Leuven transplant cohort. Transplant Proc. 2014;46:3147-53.

62. Park JE, Kim SY, Song JH, et al. Comparison of short-term outcomes for connective tissue diseaserelated interstitial lung disease and idiopathic pulmonary fibrosis after lung transplantation. J Thorac Dis. 2018;10:1538-47.

63. Wells AU, Brown KK, Flaherty KR, et al. What's in a name? That which we call IPF, by any other name would act the same. Eur Respir J. 2018;51(5):1800692.

64. Gilbane AJ, Denton CP, Holmes AM. Scleroderma pathogenesis: a pivotal role for fibroblasts as effector cells. Arthritis Res Ther. 2013;15:215.
65. Herzog EL, Mathur A, Tager AM, et al. Review: interstitial lung disease associated with systemic sclerosis and idiopathic pulmonary fibrosis: how similar and distinct? Arthritis Rheumatol. 2014;66:1967-78.

66. Wolters PJ, Blackwell TS, Eickelberg O, et al. Time for a change: is idiopathic pulmonary fibrosis still idiopathic and only fibrotic? Lancet Respir Med. 2018;6:154-60.

67. Strieter RM, Mehrad B. New mechanisms of pulmonary fibrosis. Chest. 2009;136:1364-70.

68. Bagnato G, Harari S. Cellular interactions in the pathogenesis of interstitial lung diseases. Eur Respir Rev. 2015;24:102-14.

69. King TE Jr, Bradford WZ, Castro-Bernardini S, et al. A phase 3 trial of pirfenidone in patients with idiopathic pulmonary fibrosis. $\mathrm{N}$ Engl $\mathrm{J}$ Med. 2014;370:2083-92.

70. Khanna D, Albera C, Fischer A, et al. An open-label, phase II study of the safety and tolerability of pirfenidone in patients with scleroderma-associated interstitial lung disease: the LOTUSS trial. J Rheumatol. 2016;43:1672-9.

71. Richeldi L, Du Bois RM, Raghu G, et al. Efficacy and safety of nintedanib in idiopathic pulmonary fibrosis. N Engl J Med. 2014;370:2071-82.

72. Richeldi L, Cottin V, Du Bois RM, et al. Nintedanib in patients with idiopathic pulmonary fibrosis: combined evidence from the TOMORROW and INPULSIS $^{\circledR}$ trials. Respir Med. 2016;113:74-9.

73. Wollin L, Wex E, Pautsch A, et al. Mode of action of nintedanib in the treatment of idiopathic pulmonary fibrosis. Eur Respir J. 2015;45:1434-45.

74. Wollin L, Ostermann A, Williams C. Nintedanib inhibits pro-fibrotic mediators from $\mathrm{T}$ cells with relevance to connective tissue disease-associated interstitial lung disease. Eur Respir J. 2017;50:PA903.

75. Huang J, Beyer C, Palumbo-Zerr K, et al. Nintedanib inhibits fibroblast activation and ameliorates fibrosis in preclinical models of systemic sclerosis. Ann Rheum Dis. 2016;75:883-90.

76. Huang J, Maier C, Zhang Y, et al. Nintedanib inhibits macrophage activation and ameliorates vascular and fibrotic manifestations in the Fra2 mouse model of systemic sclerosis. Ann Rheum Dis. 2017;76:1941-8.

77. Lee HY, Hur J, Kim IK, et al. Effect of nintedanib on airway inflammation and remodeling in a murine 
chronic asthma model. Exp Lung Res. 2017;43: 187-96.

78. Redente EF, Aguilar MA, Black BP, et al. Nintedanib reduces pulmonary fibrosis in a model of rheumatoid arthritis-associated interstitial lung disease. Am J Physiol Lung Cell Mol Physiol. 2018;314: L998-1009.

79. Wollin L, Distler JHW, Denton CP, et al. Rationale for the evaluation of nintedanib as a treatment for systemic sclerosis-associated interstitial lung disease. J Scleroderma Relat Dis. 2019. https://doi.org/ $10.1177 / 2397198319841842$.

80. Walsh SLF. Multidisciplinary evaluation of interstitial lung diseases: current insights: number 1 in the series "Radiology" edited by Nicola Sverzellati and Sujal Desai. Eur Respir Rev. 2017;26(144): 170002.

81. Kreuter M, Bendstrup E, Russell AM, et al. Palliative care in interstitial lung disease: living well. Lancet Respir Med. 2017;5:968-80.

82. Dowman LM, McDonald CF, Hill CJ, et al. The evidence of benefits of exercise training in interstitial lung disease: a randomised controlled trial. Thorax. 2017;72:610-9.

83. Perez-Bogerd S, Wuyts W, Barbier V, et al. Short and long-term effects of pulmonary rehabilitation in interstitial lung diseases: a randomised controlled trial. Respir Res. 2018;19:182.

84. Visca D, Mori L, Tsipouri V, et al. Effect of ambulatory oxygen on quality of life for patients with fibrotic lung disease (AmbOx): a prospective, openlabel, mixed-method, crossover randomised controlled trial. Lancet Respir Med. 2018;6:759-70.

85. Macaluso C, Furcada JM, Alzaher O, et al. The potential impact of azithromycin in idiopathic pulmonary fibrosis. Eur Respir J. 2019;53(2): 1800628.
86. Vasakova M, Morell F, Walsh S, et al. Hypersensitivity pneumonitis: perspectives in diagnosis and management. Am J Respir Crit Care Med. 2017;196:680-9.

87. Loza E, Lajas C, Andreu JL, et al. Consensus statement on a framework for the management of comorbidity and extra-articular manifestations in rheumatoid arthritis. Rheumatol Int. 2015;35: 445-58.

88. Denton CP, Khanna D. Systemic sclerosis. Lancet. 2017;390:1685-99.

89. Schwarzkopf L, Witt S, Waelscher J, et al. Associations between comorbidities, their treatment and survival in patients with interstitial lung diseasesa claims data analysis. Respir Res. 2018;19:73.

90. Distler O, Brown KK, Distler JHW, et al. Design of a randomised, placebo-controlled clinical trial of nintedanib in patients with systemic sclerosis-associated interstitial lung disease (SENSCIS). Clin Exp Rheumatol. 2017;35:75-81.

91. Flaherty KR, Brown KK, Well AU, et al. Design of the PF-ILD trial: a double-blind, randomised, placebocontrolled phase III trial of nintedanib in patients with progressive fibrosing interstitial lung disease. BMJ Open Respir Res. 2017;4:e000212.

92. Maher TM, Corte TJ, Fischer A, et al. Pirfenidone in patients with unclassifiable progressive fibrosing interstitial lung disease: design of a double-blind, randomised, placebo-controlled phase II trial. BMJ Open Respir Res. 2018;5:e000289.

93. Saunders P, Tsipouri V, Keir GJ, et al. Rituximab versus cyclophosphamide for the treatment of connective tissue disease-associated interstitial lung disease (RECITAL): study protocol for a randomised controlled trial. Trials. 2017;18:275. 